https://doi.org/10.48009/2_iis_2005_161-167

\title{
AN EXAMINATION OF ONLINE FRAUD COMPLAINT OCCURRENCES
}

\author{
Lai C. Liu, University of Texas Pan American, liul@utpa.edu \\ Kai S. Koong, University of Texas Pan American, koongk@utpa.edu \\ Margaret Allison, University of Texas Pan American, malison@utpa.edu \\ June Wei, University of West Florida, jwei@uwf.edu
}

\begin{abstract}
While it is true that the Internet has helped businesses to reach customers that were previously not accessible, it has also opened another opportunity for fraud. This study examines the occurrences of the different types of online frauds and where they were committed. Several interesting trends were found to exist in the data set. First, there were seven major types of online fraud. Second, over 50 percent of the online frauds were related to Internet auctions. Third, some types of online fraud appear to happen only in certain geographic areas or states. Fourth, the number of online fraud cases is highest in states and regions with the largest population. However, when the population was taken into account, the trend was quite different.
\end{abstract}

Keywords: Consumer Fraud, National fraud complaints, Online Fraud, National Fraud Patterns and Trends

\section{INTRODUCTION}

As a result of Internet technology, transactions processing has undergone remarkable changes. On the positive side, e-commerce and m-commerce have become a reality in the electronic marketplace. However, one of the undesirable outcomes of Internet access is its use for criminal acts. Obviously, the number of identity theft complaints is the one type of fraud that has caught the public's attention. It has been the top complaint filed with the Federal Trade Commission for four consecutive years [12]. According to the Federal Trade Commission Identity Theft Data Clearing House, 215,000 people had their identity stolen in 2003, up from 162,000 in 2002 [1, 6, $8]$. One of the reasons those numbers have been climbing so rapidly is because personal information can be obtained from everyday activities, causing individuals to unknowingly become victims. In fact, $80 \%$ of victims are unaware that their identity has been stolen at the time of the occurrence [5]. To minimize the problem, the United States Congress was forced to act by passing the Federal Identity Theft and Assumption Deterrence Act in 1998 [2]. This act established that identity theft involves of knowingly and intentionally using the identification of another individual to commit a felony.

While many studies have indicated that identity theft has been the leading type of consumer fraud, there are other major categories that have contributed to the total number of complaints filed. Internet auctions and Internet service and computer complaints have come in $2^{\text {nd }}$ and $3^{\text {rd }}$ in the last 3 years with approximately 10 percent and 7 percent of the total complaints [11]. The other top categories of consumer fraud include advance fee loans/credit repair, shop-at-home catalog sales, and foreign money offers, all of which are distributed among the different U.S. regions. 


\section{STATEMENT OF THE PROBLEM}

In 2003, there were 516,740 complaints filed with the Federal Trade Commission. Some 301,835 of the cases were in the areas of consumer fraud and 214,905 incidences were related to identity fraud. This is an increase of 112,740 from the previous year [15]. In 2003 alone, American fraud victims reported losing over $\$ 437$ million. Internet fraud accounted for more than half of the total losses with a contribution of $\$ 200$ million [10].

Ten million of these cases occurred in 2002 alone with an estimated $\$ 5$ billion cost to consumers and $\$ 48$ billion cost to businesses. The estimated individual loss is approximately $\$ 500$ and the average business loss is approximately $\$ 4800$ [9]. Corporate directors are now expected to take active roles in preventing and minimizing losses caused by consumer fraud. By doing this, corporate and consumer liability can be reduced as well [13].

\section{STATEMENT OF THE OBJECTIVE}

This study examines the different types of consumer online fraud and the contributions of the top five cities in each state to the problem. Specifically, this study identifies where the fraud occurrences are committed, what types of fraud are most common, and are there any identifiable trends in ways those frauds are committed. The primary data used was extracted from the 2003 Consumer Sentinel Report [3,4]. The secondary data set, the population for each state, was obtained from the Census estimates for 2003.

This study should be of interest to federal law enforcement agencies such as the Federal Bureau of Investigation, local law enforcement entities, online fraud experts, and consumer protection advocates and agencies. In addition, the results of this study should also be of interest to all users of online systems and individuals involved in computer and information systems security design and development. Computing educators in particular, can use the outcomes reported in this study for the development and design of new curriculum and course content that can help to minimize online fraud.

\section{METHODOLOGY}

The targeted population of this study consists of online fraud victims in each of the fifty states and the District of Columbia. In particular, the data used in this study were obtained from the Federal Trade Commission report called the Consumer Sentinel and it covered all fraud cases that were reported during the 2003 calendar year [7]. The four primary set of variables extracted from this report are: namely, (a) state names, (b) total number of fraud cases for the respective states, (c) top 5 types of fraud cases in each state, and (d) total number of fraud cases for each of the top 5 types of fraud.

To begin, the United States was divided into four major geographical regions, associated subregions, and their member states [14]. Based on the classification used by the Population Division of U.S. Census Bureau, the regions sub-regions and member states are as follows: 
1. Northeast: (a) New England - Connecticut, Maine, Massachusetts, New Hampshire, Rhode Island, and Vermont, (b) Middle Atlantic - New Jersey, New York, and Pennsylvania

2. Midwest: (a) East North Central - Illinois, Indiana, Michigan, Ohio, and Wisconsin, (b) West North Central - Iowa, Kansas, Minnesota, Missouri, Nebraska, North Dakota, and South Dakota.

3. South: (a) South Atlantic - Delaware, District of Columbia, Florida, Georgia, Maryland, North Carolina, South Carolina, Virginia, and West Virginia, (b) East South Central Alabama, Kentucky, Mississippi, and Tennessee, (c) West South Central - Arkansas, Louisiana, Oklahoma, and Texas.

4. West: (a) Mountain - Arizona, Colorado, Idaho, Montana, Nevada, New Mexico, Utah, and Wyoming, (b) Pacific - Alaska, California, Hawaii, Oregon, and Washington.

Second, the population of each region and sub-region was computed by adding the population of affected states. The percent of each region's and sub-region's population affected by fraud was found by dividing the number of complaints by the computed population totals. Third, the number of fraud cases in the top 5 cities of the states was then added to generate the totals for the respective regions and sub-regions. Then, the top five cities' share of the total regional cases as well as sub-regions was obtained by dividing the sum of complaints by the computed population totals in each state's top 5 cities by the regional complaints. Finally, to add more insight into the findings of this study, the fifteen categories of fraud were also divided into geographical regions. This was to highlight which complaints were more prevalent in the respective regions or subregions. The number of times a complaint appeared in a state's top five fraud category was accumulated in order to generate the fraud complaint contribution to the top five fraud complaints in each state. This information was then organized into regions to find any kind of trend between geographical region and type of complaint.

Three tables were constructed from all the data collected. The first table identifies the geographic region contribution to the total number of national fraud complaints. The second table shows the contribution of the top five cities of each state to the region examined. The last table identifies the contribution of each fraud category to the top 5 fraud complaints in each region.

\section{FINDINGS}

Based on the number of online fraud cases reported, the percentage that each of the nine subregions contributed to the national number of fraud complaints varied from $4.03 \%$ to $17.50 \%$. The percentage that each of the four geographic regions contributed to the national number of fraud complaints varied from $16.30 \%$ to $29.5 \%$. The South region has the most complaints, with more than half coming from the South Atlantic sub-region. Complaints from the South region make up almost $30 \%$ of the national number of complaints. In fact, this region has almost twice the amount of complaints as the Northeast region. The West region has the second highest number of complaints with more than $70 \%$ of its complaints coming from the Pacific sub-region.

When the population was taken into account, the trends were quite different. For example, the West region was the most affected by fraud with $.1088 \%$ of the population filing complaints. The range of population affected in each sub-region was between $.0686 \%$ and $.1091 \%$. Interestingly, the South has the lowest percentage of complaints when the population was taken into account. 
Previously, the Northeast has the lowest number of complaints but it has the second highest percent of population affected by fraud. The Pacific sub-region is the sub-region with the highest percent of its population affected by fraud. Even though the New England sub-region has the second lowest amount of complaints, it is the fourth highest sub-region of the nine affected by fraud. Details about the patterns in the raw data set and its behavior when the population was taken into account for are presented in Table 1.

Table 1. Regional Contribution to National Fraud Complaints

\begin{tabular}{|c|c|c|c|c|}
\hline Geographic Region & Number of Complaints & $\begin{array}{c}\text { Population of } \\
\text { Area }\end{array}$ & $\begin{array}{l}\text { Percentage from } \\
\text { National Fraud } \\
\text { Complaints }\end{array}$ & $\begin{array}{c}\text { Percent from } \\
\text { Population of Area }\end{array}$ \\
\hline Northeast & 49,201 & $54,399,446$ & $16.30 \%$ & $0.0904 \%$ \\
\hline New England & 13,195 & $14,205,480$ & $4.37 \%$ & $0.0929 \%$ \\
\hline Middle Atlantic & 36,006 & $40,193,966$ & $11.93 \%$ & $0.0896 \%$ \\
\hline Midwest & 53,632 & $65,406,134$ & $18.76 \%$ & $0.0866 \%$ \\
\hline East N. Central & 39,816 & $45,839,269$ & $13.19 \%$ & $0.0869 \%$ \\
\hline West N. Central & 16,816 & $19,568,865$ & $5.57 \%$ & $0.0859 \%$ \\
\hline South & 89,177 & $104,538,348$ & $29.54 \%$ & $0.0853 \%$ \\
\hline South Atlantic & 52,831 & $54,344,651$ & $17.50 \%$ & $0.0972 \%$ \\
\hline East S. Central & 12,164 & $17,341,608$ & $4.03 \%$ & $0.0686 \%$ \\
\hline West S. Central & 24,182 & $32,852,089$ & $8.01 \%$ & $0.0736 \%$ \\
\hline West & 72,290 & $66,465,849$ & $23.95 \%$ & $0.1088 \%$ \\
\hline Mountain & 20,911 & $19,383,929$ & $6.93 \%$ & $0.1079 \%$ \\
\hline Pacific & 51,379 & $47,081,920$ & $17.02 \%$ & $0.1091 \%$ \\
\hline
\end{tabular}

The percentages that the top five cities contributed to the total amount of cases in its respective sub-region ranged from $24.64 \%$ to $51.45 \%$. The percentage that the top five cities contributed to each region ranged from $25.67 \%$ to $32.39 \%$. The percentages of complaints in the top 5 cities from the sub-region's total population ranged from $.0193 \%$ to $.0555 \%$ while the regions ranged from $.0232 \%$ to $.0352 \%$. The highest percentage of complaints from the states' top five cities compared to total cases comes from the Mountain sub-region with 51.45\% and is reinforced with $.0555 \%$ of the sub-region's total population being affected. The West region has the highest amount of complaints coming from its top five cities. The South region has twice the number of complaints coming form its top five cities as the Northeast. The South Atlantic sub-region contributes more than half of the population to the South region and also has the highest percent of its population in the region affected by fraud in its top five cities. Details showing the effect those complaints in the top five cities from each state in each region have on the total population are presented in Table 2. 
Table 2. Contribution the Top Five Fraud Cities of Each State Have on Each Region

\begin{tabular}{|c|c|c|c|c|c|}
\hline $\begin{array}{l}\text { Geographic } \\
\text { Region }\end{array}$ & $\begin{array}{c}\text { Total } \\
\text { Complaints in } \\
\text { Top } 5 \text { Cities }\end{array}$ & $\begin{array}{c}\text { Total Cases in } \\
\text { Region }\end{array}$ & $\begin{array}{c}\text { Percentage } \\
\text { Top } 5 \text { Cities } \\
\text { from Total } \\
\text { Cases }\end{array}$ & $\begin{array}{c}\text { Total } \\
\text { Population in } \\
\text { Region }\end{array}$ & $\begin{array}{c}\text { Percentage of } \\
\text { Complaints in } \\
\text { Top } 5 \text { Cities to } \\
\text { Total Population }\end{array}$ \\
\hline Northeast & 12,623 & 49,174 & $25.67 \%$ & $54,399,446$ & $0.0232 \%$ \\
\hline New England & 2,740 & 13,195 & $20.77 \%$ & $14,205,480$ & $0.0193 \%$ \\
\hline Middle Atlantic & 9,883 & 35,979 & $27.47 \%$ & $40,193,966$ & $0.0246 \%$ \\
\hline Midwest & 15,209 & 47,632 & $31.93 \%$ & $65,406,134$ & $0.0233 \%$ \\
\hline East N. Central & 9,460 & 30,816 & $30.70 \%$ & $45,837,269$ & $0.0206 \%$ \\
\hline West N. Central & 5,749 & 16,816 & $34.19 \%$ & $19,568,865$ & $0.0294 \%$ \\
\hline South & 26,122 & 88,260 & $29.60 \%$ & $104,538,384$ & $0.0250 \%$ \\
\hline South Atlantic & 14,006 & 51,914 & $26.98 \%$ & $54,344,651$ & $0.0258 \%$ \\
\hline East S. Central & 3,857 & 12,164 & $31.71 \%$ & $17,341,608$ & $0.0222 \%$ \\
\hline West S. Central & 8,261 & 24,182 & $34.16 \%$ & $32,852,089$ & $0.0251 \%$ \\
\hline West & 23,418 & 72,290 & $32.39 \%$ & $66,465,849$ & $0.0352 \%$ \\
\hline Mountain & 10,758 & 20,911 & $51.45 \%$ & $19,383,929$ & $0.0555 \%$ \\
\hline Pacific & 12,660 & 51,379 & $24.64 \%$ & $47,081,920$ & $0.0269 \%$ \\
\hline
\end{tabular}

Table 3. Fraud Complaints Contribution to Top 5 Fraud Complaints in each State

\begin{tabular}{|c|c|c|c|c|c|c|c|}
\hline $\begin{array}{c}\text { Geographical } \\
\text { Region }\end{array}$ & $\begin{array}{l}\text { Advance } \\
\text { Fee } \\
\text { Loans/ } \\
\text { Credit } \\
\text { Repair }\end{array}$ & $\begin{array}{l}\text { Business } \\
\text { Opps. } \\
\text { and } \\
\text { Work-at- } \\
\text { Home } \\
\text { Plans }\end{array}$ & $\begin{array}{c}\text { Foreign } \\
\text { Money } \\
\text { Offers }\end{array}$ & $\begin{array}{l}\text { Internet } \\
\text { Auctions }\end{array}$ & $\begin{array}{c}\text { Prizes/ } \\
\text { Sweep- } \\
\text { stakes } \\
\text { and } \\
\text { Lotteries }\end{array}$ & $\begin{array}{l}\text { Shop-at- } \\
\text { home } \\
\text { Catalog } \\
\text { Sales }\end{array}$ & $\begin{array}{c}\text { Internet } \\
\text { Service and } \\
\text { Loan } \\
\text { Complaints }\end{array}$ \\
\hline Northeast & 2500 & 0 & 821 & 14549 & 3348 & 8805 & 5403 \\
\hline New England & 342 & 0 & 821 & 3837 & 752 & 2243 & 1579 \\
\hline Middle Atlantic & 2158 & 0 & 0 & 10712 & 2596 & 6562 & 3824 \\
\hline Midwest & 3174 & 0 & 909 & 15231 & 4844 & 9041 & 5849 \\
\hline East North Central & 2479 & 0 & 377 & 10703 & 3311 & 6468 & 4001 \\
\hline West North Central & 695 & 0 & 532 & 4528 & 1533 & 2573 & 1848 \\
\hline South & 6442 & 0 & 4801 & 21891 & 2919 & 13513 & 10251 \\
\hline South Atlantic & 3991 & 0 & 3060 & 12521 & 1398 & 7813 & 6328 \\
\hline East South Central & 821 & 0 & 293 & 3138 & 1043 & 1920 & 1277 \\
\hline West South Central & 1702 & 0 & 1448 & 6232 & 478 & 3780 & 2646 \\
\hline West & 609 & 190 & 4193 & 19222 & 5997 & 11390 & 8315 \\
\hline Mountain & 389 & 190 & 971 & 5015 & 2071 & 3003 & 2174 \\
\hline Pacific & 220 & 0 & 3222 & 14207 & 3926 & 8387 & 6141 \\
\hline
\end{tabular}

Table 3 separates the consumer fraud complaints into fifteen major categories. This table accounts for the number of times each category has been recorded as a state's top 5 complaint. 
Seven types of fraud complaints accounted for most of the top five complaints for each state. They included advance fee loans/credit repair, business opportunities and work-at-home plans, foreign money offers, Internet auctions, Internet service and loan complaints, prizes/sweepstakes and lotteries, and shop-at-home catalog sales. Of these, Internet auctions accounted for the highest in each region and sub-region. This coincides with the amount of Internet auction complaints filed in 2002, which accounted for $13 \%$ of all complaints ("Fraud rises with ID theft on top," 2003). The lowest number of complaints to reach the top 5 was business opportunities and work-at-home plans, with 190 from the West region. This entire amount was concentrated only in the state of Nevada. Losses for this fraud type in the United States account for more than $\$ 100$ million a year. Other major observations include the following:

- The middle Atlantic contributed about $86 \%$ of the total cases of advance fee loans and credit repair fraud reported in the Northeast.

- In the Northeast, Foreign Money Order complaints came only from the New England subregion.

- About $76.8 \%$ of the Foreign Money order complaints in the West came from the Pacific subregion.

- Of the Prizes/Sweepstake and Lottery complaints in the Northeast, approximately $78 \%$ were located in the Middle Atlantic sub-region.

\section{CONCLUSIONS, IMPLICATIONS AND LIMITATIONS}

Seven of the 16 types of online crimes identified were found to have played a major role in the top 5 cities of each state. First, business opportunities and work at home schemes, one of the seven major online fraud types, were primarily committed in the Mountain sub-region. Actually, this type of online crime was found to be germane to the state of Nevada. This is good news because efforts at eliminating this category of crime can now be focused on this state.

Second, among the crimes that affected commerce the most, Internet auctions account for over 50 percent of all the online crimes. Based on the population of the respective regions, it appears that all the regions are victimized at about the same rate. Efforts aimed at minimizing this type of online crime will therefore require a nationwide effort that is targeted at end-users of Internet auctions.

Third, foreign money offer crimes are mostly committed in the South and West regions. A possible reason for its popularity can be attributed to the larger number of migrants in these two regions. A possible way to reduce this fraud group is to provide best practices guidelines to minority and migrant groups through community outreach efforts. To be effective, some of this information may have to be printed in the languages of groups that are most affected.

Finally, while it is true that more crimes are committed in states with larger population, the percentage of crimes relative to the population can be quite different. Actually, when the population and the state's ranking in the digital divide are taken into account, it was found that the crime rate was highest in states that had high computer as well as Internet access. In other words, the Internet is indeed a medium that does not discriminate by geography. Rather, it is at the level of access where they are divided. 
This study is limited to online fraud that is classified as Internet fraud. Another limitation of this study is that there was no data available on the number of complaints for categories that are not listed as a state's top 5 complaints. Third, the 2003 population that was used is based on an estimate because the U.S. Census is only taken every ten years. Limitations also include the fact that not all cases of consumer fraud are reported, which means that the numbers used in our study do not really reflect everyone victimized by fraud. Another possible cause of inaccurate information in our study was that percentages of consumer fraud types can total to more than 100 percent. This is because some victims report experiencing fraud more than once.

It should be pointed out here that despite the limitations stated, the data gathered and analyzed in this study can have multiple uses for various agencies in reducing fraud. For future studies, further research focusing on yearly regional trends and discovering the types of fraud affecting each of the top five cities may be useful to law enforcement in preventing fraud from occurring. Last but not least, given the progresses made in Internet technology, it can be expected that the number and variety of methods used by criminals will increase.

\section{REFERENCES}

1. Anderson, L., O’Brien J., \& Orbuch, D. (2004). Identity Theft-A Compliance Officer's Next Generation of Concerns. Journal of Health Care Compliance, 5-7.

2. Ashman, J., Franzis, J., Harris, C., Langdon, D., Simoncelli, W., Smith, C., et al. (2002). Identity Theft: Possible Implications for Property and Casualty Insurance. CPCU eJournal, $55,1-14$.

3. Consumer Sentinel. (2004a). Appendix C: Sentinel Top Complaint Categories Three-Year Trends. Retrieved Sept. 20, 2004 from www.consumer.gov/sentinel/

4. Consumer Sentinel. (2004b). Fraud Complaints by Consumer State. Retrieved Sept. 20, 2004 from www.consumer.gov/sentinel/

5. Diller-Haas, A. (2004). Identity Theft: It Can Happen to You. CPA Journal, 74, 42-45.

6. Dwan, B. (2004). Identity Theft. Computer Fraud and Security, 1-7.

7. Federal Trade Commission. (2004). FTC Releases Top 10 Consumer Complaint Categories in 2003. Retrieved Sept. 22, 2004, from www.ftc.gov/opa/2004/01/top10.htm.

8. Fraud Rises with ID Theft on Top. (2003). Computer Fraud and Security, 2.

9. Holt, T. (2004). The Fair and Accurate Credit Transactions Act: New tool to fight identity theft. Business Horizon, 47, 3-6.

10. Identity Theft, Internet Scams Rise, FTC Says. (2004). Congress Daily, 10.

11. Internet Involved in Top Three Fraud Complaints. (2002). Journal of Internet Law, 22.

12. Lorek, L. (2004, 23 January). San Antonio is Third in Texas for Number in Identity-Theft Reports, San Antonio Express News.

13. Phillippson, S., \& Thomas, S. (2003). E-Fraud-What Companies Face Today. Computer Fraud and Security, 7-9.

14. Population Division U.S. Census Bureau. (2004). Annual Estimate of the Population for the United States, Regions, and Divisions: April 1, 2000 to July 1, 2003. Retrieved Oct. 19, 2004 from www.census.gov.

15. Swartz, N. (2004). ID Theft Tops FTC Complaints Again. The Information Management Journal, $38,8$. 